\title{
Research
}

\section{Mapping the World's Intact Forest Landscapes by Remote Sensing}

\author{
$\underline{\text { Peter Potapov }}^{1}$, Aleksey Yaroshenko $^{2}, \underline{\text { Svetlana Turubanova }}^{2}$, Maxim Dubinin $^{3}{ }^{3}$ Lars Laestadius $^{4}$, \\ Christoph Thies $^{5}$, Dmitry Aksenov $^{6}$, Aleksey Egorov $^{2}$, Yelena Yesipova $^{6}$, Igor Glushkov ${ }^{6}$, \\ Mikhail Karpachevskiy $^{7}$, Anna Kostikova $^{6}$, Alexander Manisha $^{6}$, Ekaterina Tsybikova $^{6}$, and \\ Ilona Zhuravleva $^{2}$
}

\begin{abstract}
Protection of large natural forest landscapes is a highly important task to help fulfill different international strategic initiatives to protect forest biodiversity, to reduce carbon emissions from deforestation and forest degradation, and to stimulate sustainable forest management practices. This paper introduces a new approach for mapping large intact forest landscapes (IFL), defined as an unbroken expanse of natural ecosystems within areas of current forest extent, without signs of significant human activity, and having an area of at least $500 \mathrm{~km}^{2}$. We have created a global IFL map using existing fine-scale maps and a global coverage of high spatial resolution satellite imagery. We estimate the global area of IFL within the current extent of forest ecosystems (forest zone) to be 13.1 million $\mathrm{km}^{2}$ or $23.5 \%$ of the forest zone. The vast majority of IFL are found in two biomes: Dense Tropical and Subtropical Forests (45.3\%) and Boreal Forests (43.8\%). The lowest proportion of IFL is found in Temperate Broadleaf and Mixed Forests. The IFL exist in 66 of the 149 countries that together make up the forest zone. Three of them-Canada, Russia, and Brazil - contain $63.8 \%$ of the total IFL area. Of the world's IFL area, $18.9 \%$ has some form of protection, but only $9.7 \%$ is strictly protected, i.e., belongs to IUCN protected areas categories I-III. The world IFL map presented here is intended to underpin the development of a general strategy for nature conservation at the global and regional scales. It also defines a baseline for monitoring deforestation and forest degradation that is well suited for use with operational and cost-effective satellite data. All project results and IFL maps are available on a dedicated web site (http://www.intactforests.org).
\end{abstract}

Key Words: Forest degradation, Globalforest assessment, Intactness, Landsat, Remote sensing, Wilderness

\section{INTRODUCTION}

As the most biologically diverse terrestrial ecosystem, forests provide critical habitats to more than half of all known plant and animal species on Earth (Secretariat of the Convention on Biological Diversity (SCBD) 2001, Hassan et al. 2005). Forests and the non-forest ecosystems associated with them (e.g., wetlands and mountain grasslands) maintain environmental conditions and provide ecosystem services at both regional and global scales: from regional hydrological cycles to global climate constituents. Forest biomes, including tropical, temperate, and boreal forests, play a crucial role in mitigating climate change by serving as carbon sinks (Matthews et al. 2000, Hassan et al. 2005) and carbon storage, containing up to $80 \%$ of all aboveground and approximately $40 \%$ of all belowground terrestrial carbon (Dixon 1994). The basic provisional (timber, food, and forage) and supporting (water purification, climate regulation) ecosystem services provided by forests are essential for human well-being.

As a source of timber and non-timber resources, forests are increasingly exploited for industrial and subsistence purposes for the benefit of hundreds of millions of people worldwide. The forest extent has rapidly declined throughout human history as a result of agricultural expansion, urban development, mining operations, etc (Food and Agriculture Organization (FAO) 2005, Hassan et al. 2005). Destructive modes of economic development have led to the rapid deforestation, fragmentation, and 
degradation of forest and non-forest ecosystems within forest biomes. This process has resulted in a loss of forest biodiversity, great increases in greenhouse gas emissions, and degradation of the ability of forests to maintain other core ecosystem services (Houghton et al. 1991, Bryant et al. 1997, SCBD 2001, FAO 2005, Hassan et al. 2005).

Protection of large natural forest landscapes is a highly important task to help fulfill different international strategic initiatives to protect forest biodiversity (SCBD 2001), to reduce carbon emissions from deforestation and forest degradation (International Geosphere-Biosphere Programme (IGBP) 1998, Mollicone et al. 2007), and to stimulate use of sustainable forest management practices (Forest Stewardship Council (FSC) 2004). There are three reasons to focus on large undeveloped forest areas. First, the ability of ecological systems to support the natural diversity of species and communities, and their ability to absorb disturbance (resistance) and recover from disturbance (resilience), is enhanced if they have little or no human interference and the area is large enough to support core ecological processes (Noss 1990, Anderson 1991, FAO 2002). Second, the conservation value of forest landscapes that remain undeveloped and unfragmented by human infrastructure is high, although it may vary between regions. Large natural forest areas are important for the preservation of all strata of biological diversity (Harris 1984, Noss 1990, Turner 1996), and for maintaining ecological processes and services like water and air purification, nutrient cycling, carbon sequestration, erosion, and flood control (Bryant et al. 1997, Yaroshenko et al. 2001). Third, large unpopulated areas are often comparatively cheap to conserve, as their remoteness and low current economic value protect them from human disturbance (Yaroshenko et al. 2001, Mollicone et al. 2006).

Measuring human influence in forest ecosystems worldwide is a daunting task. The vast extent of the area to be analyzed requires the mobilization of extensive resources. Global assessment of human influence on natural ecosystems via mapping of relatively undeveloped areas has been prototyped within the last 20 years (McCloskey and Spalding 1989, Bryant et al. 1997, Sanderson et al. 2002, Kareiva et al. 2007). However, all cited maps were created on the basis of expert knowledge and geographic metrics, such as human population density, settlements, roads, etc. None of these earlier efforts made use of contemporary satellite data that enable precise mapping of infrastructure development and areas affected by recent anthropogenic disturbances.

This paper introduces a new approach for assessing human influence on forest landscapes that combines relevance at the regional level with global scope. The essence of the approach is to use high spatial resolution satellite information to establish the boundaries of large undeveloped forest areas, socalled intact forest landscapes (IFL), and to use these boundaries as a baseline for monitoring. Our definition of IFL is based on the concepts of ecological integrity and intactness (Noss 1990, Anderson 1991, Bryant et al. 1997).

The world IFL map presented here is the first global assessment based on high spatial resolution Landsat satellite imagery. Landsat data sets have previously been used in a number of forest analysis applications, including mapping of land cover, landcover change, and analysis of human disturbances (Iverson et al. 1989, Woodcock et al. 2001). One of the most important merits of Landsat imagery is the availability of data collections at no cost, e.g., as made available through the Global Land Cover Facility (http://www.glcf.umiacs.umd.edu). These free global data sets allowed us to map disturbances and infrastructure directly and precisely, to create a fine-scale IFL map, and to produce area estimates.

The global map builds upon a number of regional IFL maps that were produced in 2001-2006, using similar methods, by a group of scientists and environmental non-governmental organizations (NGOs) under the framework of Global Forest Watch-an initiative of the World Resources Institute (WRI). In the following, we provide a detailed comparison of our results with previous global intactness and human influence maps (McCloskey and Spalding 1989, Bryant et al. 1997, Sanderson et al. 2002).

\section{DATA AND MAPPING ALGORITHM}

\section{Intact Forest Landscapes-Definition and Criteria}

We define an IFL as an unbroken expanse of natural ecosystems within the zone of current forest extent, showing no signs of significant human activity, and large enough that all native biodiversity, including 
viable populations of wide-ranging species, could be maintained. Although all IFLs are within the forest zone, some may contain extensive naturally treeless areas, including grasslands, wetlands, lakes, alpine areas, and ice. This definition builds on the definition of frontier forest that was developed by the WRI (Bryant et al. 1997). The frontier forest definition captures several fundamental ecological characteristics of forest ecosystems: stability, biodiversity, and resistance to natural disturbances, but as it was based on broad types of intactness criteria, it was not suitable for rapid area assessment and mapping using remotely sensed data. We developed and used the IFL definition to achieve two important objectives: (1) to formalize a replicable procedure for analysis of disturbance and fragmentation in forest landscapes at a regionally and nationally relevant scale, and (2) to produce a globally consistent map of remaining intact areas that is suitable for underpinning the targeting of conservation work at these levels. As a consequence of the second objective, we used a discrete classification of landscapes (i.e., intact vs. nonintact) rather than degree of intactness (i.e., a continuous variable).

To locate areas that satisfy the IFL definition, we have developed a set of criteria. These criteria were designed to be globally applicable and easily replicable, allowing for repeated assessments over time as well as verification by independent replication of assessments. Criteria were separated into two groups to be applied in sequence; the first group is used to assess the spatial extent of developed areas and the second to assess fragmentation. The groups of criteria are discussed below.

\section{Criteria of Developed Areas}

To find areas minimally influenced by human activities, we applied an "inverse" logic. Having first identified our area of study (the area or zone of current forest extent), we posed as the nullhypothesis that the entire area remains intact, i.e., unaffected by significant human influence, and then gathered evidence to prove the opposite, such as indications of active or recent use, like clearing for agriculture, logging, and infrastructure development. Thus, we systematically identified and eliminated areas of human development from our area of study, reducing it down to the point where no more exclusion could be made for lack of evidence. We assumed an area to be intact if we could find no evidence of significant human influence.

Only recent and intensive development activities were considered significant. Evidence of lowintensity and old disturbances, such as shifting cultivation in ancient times, forest grazing, lowintensity selective logging, and hunting, was treated as "background" influence and not eliminated. In summary, areas with evidence of the following types of human influence were eliminated: (1) settlements (a buffer of $1 \mathrm{~km}$ was applied); (2) infrastructure used for transportation between settlements or for industrial development of natural resources, including roads (except unpaved trails), railways, navigable waterways (including seashore), pipelines, and power transmission lines (a buffer of $1 \mathrm{~km}$ on each side was applied); (3) areas used for agriculture and timber production; and (4) areas affected by industrial activities during the last 30 70 years, such as logging, mining, oil and gas exploration and extraction, peat extraction, etc. The width of buffer zones, i.e., of human-impact zones along roads and settlements, was chosen by estimation of the extent to which human influence typically penetrates into the adjacent landscape. The use of a buffering approach also helps to remove areas more likely to be affected by intensive selective logging. Conservative buffers were chosen; many studies have shown that the influence of infrastructure exceeds $1 \mathrm{~km}$ for birds, predators, and ungulates (Gucinski et al. 2001).

Forest fires are a natural component of forest dynamics in some regions (e.g., boreal forests), but human development significantly alters natural fire regimes (Mouillot and Filed 2005, Mollicone et al. 2006). The logic of our approach calls for a separation of burned areas by cause (natural vs. anthropogenic) but making this separation based on post facto remote-sensing data is impossible. The following decision rule was therefore applied: areas affected by stand-replacing wildfires during the last 30-70 years were eliminated if located in the vicinity of infrastructure or developed areas; fire scars within undeveloped forest landscapes were assumed to have natural causes and were not used as a reason for an area to be eliminated. 


\section{Criteria of Fragmentation}

The following size criteria were used to delineate a patch of IFL: (1) larger than $500 \mathrm{~km}^{2}$; (2) at least 10 $\mathrm{km}$ wide at the broadest place (measured as the diameter of the largest circle that can be fitted inside the patch); and (3) at least $2 \mathrm{~km}$ wide in corridors or appendages to areas that meet the above criteria. Our choice of threshold value was informed by a combination of ecological and practical criteria. We considered existing knowledge of the minimum area required to sustain viable populations of large forest mammals (Rudis and Tansey 1995, Rodriguez and Delibes 2003). Such areas are likely to be capable of maintaining most natural values and functions of the remaining self-sustaining forest landscape, including natural disturbance processes at different scales (wildfires, storm damages, insect outbreaks, etc.); natural spatial patterns of ecosystems and habitats; viable populations of plants and animals, including wide-ranging predators and prey; and resistance to influences from adjoining disturbed or fragmented areas (Wilcox and Murphy 1985, Turner 1996, Ferraz et al. 2003).

We also considered the practical requirements of making a global assessment at a regionally relevant scale. It was deemed important by many experts to design a method that would reduce the time and cost down to a feasible level (i.e., to a level where it could be completed with available resources). Thus, the choice of size criteria represents a pragmatic compromise that makes the method ecologically meaningful yet also allows it to be executed in a timely fashion and repeated over time.

\section{Maps and Remotely Sensed Data Used}

Fine-scale electronic maps of settlements and transportation networks were used to detect areas of heavy industrial development and fragmentation. These data sets were available only for a limited number of countries (see "Mapping algorithm" below). For some regions, such as Eastern Europe, tropical Africa, and Indonesia, scanned topographical maps were used, but for most regions the topographical maps were significantly out of date and were used mainly for reference during the analysis of satellite images.

Satellite data were used to identify developed or anthropogenically disturbed areas and to map elements of infrastructure. High spatial resolution images from Landsat Thematic Mapper (TM, global coverage representing an average date of 1990, 30$\mathrm{m}$ spatial resolution) and Enhanced Thematic Mapper plus (ETM+, global coverage representing an average date of 2000, 30-m spatial resolution) were used as the primary data source to identify IFLs. The Landsat images were obtained from the GeoCover Landsat Orthorectified image collection (Tucker et al. 2004). Three TM/ETM+ reflective bands were used: band 3 (red, 630-690 nm), band 4 (near infrared, 775-900 nm), and band 5 (midinfrared, 1550-1750 nm). The 5-4-3 band combination was used for image interpretation.

For some northern regions of Eastern Siberia, we used medium spatial resolution satellite images (Resource MSU-SK, 150-m resolution) because of lack of better data at the time of analysis. The Resource satellite images were provided by the Research and Development Center ScanEx, Russia. The band 1 (green, 540-600 nm), band 2 (red, 600$720 \mathrm{~nm}$ ), and band 4 (near infrared, $810-1000 \mathrm{~nm}$ ) were used. The 4-2-1 band combination was used for image interpretation.

\section{Mapping Algorithm}

The current extent of forest ecosystems (which we call the forest zone) was chosen as the area of study. The forest zone boundary was defined using a global tree canopy cover data set (part of the Vegetation Continuous Fields MODIS $500 \mathrm{~m}$ product, hereafter referred to as VCF) (Hansen et al. 2003). Forest was defined as an area with a year 2000 tree canopy cover greater than $20 \%$. The minimum forest patch size considered as part of the forest zone was $4 \mathrm{~km}^{2}$. The forest zone embodied all non-forest areas (including lakes and rivers) included within forest ecosystems. Fragments of the forest zone smaller than $500 \mathrm{~km}^{2}$ were not considered in the analysis.

A preliminary fragmentation analysis was then carried out for those countries having GIS data sets of transportation infrastructure and settlements (on a scale 1:500 000-1:10 000), including Russia, Canada, USA, Australia, New Zealand, Japan, and most of the countries of Central America. The analysis was based on a buffering approach: buffers were defined around roads, pipelines, power lines, and settlements, and the buffer zone subsequently eliminated from the area of study. Our goal was to identify fragments free from major elements of infrastructure and greater than $500 \mathrm{~km}^{2}$ in size. 
Areas that did not qualify were eliminated from further consideration, whereas other areas were retained as candidates for IFLs.

The second step of our two-step process-after the preliminary fragmentation analysis-was to use high spatial resolution Landsat images to systematically assess all remaining candidate IFL areas for anthropogenic disturbance, and to delineate developed and fragmented areas. The image analysis was conducted through expert-based visual interpretation, using geographic information system (GIS) overlays with additional thematic and topographic map layers. The purpose was to identify areas fragmented by infrastructure (e.g., roads, pipelines, power lines), converted to agricultural lands, or significantly influenced by industrial development during the last 30-70 years (e.g., by logging, mining, and the consequences of anthropogenic fires). Disturbed and fragmented patches were eliminated from the area of study and remaining areas, if large enough, were classified as IFLs. Figure 1 shows examples of the results from the second step of the IFL mapping (i.e., results of visual interpretation of developed and fragmented areas).

To improve the quality of interpretation for most of the analyzed area, we used two sets of Landsat TM/ ETM+ images simultaneously, representing the approximate points of time of 1990 and 2000. The newer images made it possible to detect the most recent disturbances, and the older images allowed us to detect older disturbances, whose traces have become less evident with time. This was especially important in tropical forests, where the evidence of human influence disappears much faster than in temperate and boreal forests. Using imagery covering a broad time period also helped us fill the data gaps caused by the frequent cloud cover in some parts of the forest zone.

\section{Comparison with Previous Studies}

We provided the comparison of our results with previous global intactness and human influence maps within our area of study. We were able to make a direct comparison with the publicly available digital versions of the Wilderness Areas map (McCloskey and Spalding 1989; available at http:// www.grid.unep.ch/) and the Frontier Forests map (Bryant et al. 1997; available at http://www.globalf orestwatch.org/), but not with the Human Footprint map (Sanderson et al. 2002; available at http://www .ciesin.columbia.edu/wild areas/), which uses a continuous (gradual) index of human influence (as opposed to a discrete classification). To enable comparison of our results with Human Footprint map, we used a low human influence index threshold value (0-10) and the same minimum patch size as in our study $\left(500 \mathrm{~km}^{2}\right)$ to derive a map of intact areas comparable with our data.

\section{RESULTS}

\section{World's Intact Forest Landscapes}

The current extent of the world's forest zone, as defined above, is 55.9 million $\mathrm{km}^{2}$ or $37.3 \%$ of the Earth's total land area. This area can be divided into two major forest types, based on tree canopy density according to VCF: "closed forests" with tree canopy density greater than $40 \%$ represent $49.2 \%$, and "open forests and woodlands" with a tree canopy density of $20-40 \%$ comprise $24.7 \%$. "Non-forest ecosystems" (where tree canopy density is below $20 \%$ ), such as savannas, grasslands, wetlands, mountain ecosystems, lakes, etc. make up the remaining $26.1 \%$ of the forest zone.

Intact forest landscapes comprise 13.1 million $\mathrm{km}^{2}$ or $23.5 \%$ of the forest zone (Fig. 2). Most of this area is in "closed forests" $(64.5 \%)$, with the remainder spread over "open forests and woodlands" (20.5\%) and "non-forest ecosystems" $(15.0 \%) ; 30.8 \%$ of the world's "closed forests" remain intact.

The global distribution of IFLs reflects differences in history and intensity of economic development. In the boreal regions of North America and Asia, most of the remaining IFLs are located in the far north and in mountainous areas, i.e., often beyond the limits of economic accessibility. The long history of intensive land use is particularly evident in Europe, where large tracts of IFL remain only in northwestern Russia and in isolated tracts in northern Finland and Sweden. In tropical regions, IFLs are found mainly in the large tropical forests of the Amazon and Congo Basins, and in Southeast Asia on the islands of Borneo and New Guinea. The extent of some of these areas may have been overestimated in our study, especially in Central Africa, as we did not attempt to assess the effects of low-intensity human influence, such as hunting and small-scale slash-and-burn agriculture. 
Fig. 1. Examples of IFL boundaries (yellow line) mapped on Landsat ETM+ images (band combination used is 5-4-3). (A) Democratic Republic of the Congo. Settlements, agricultural areas, and buffered area along the road have been excluded. (B) Democratic Republic of the Congo. Savanna grazing areas affected by annual human-induced fires have been excluded. (C) Papua-New Guinea. Logging concession areas have been excluded. (D) Northern European Russia. Clearcuts have been excluded.
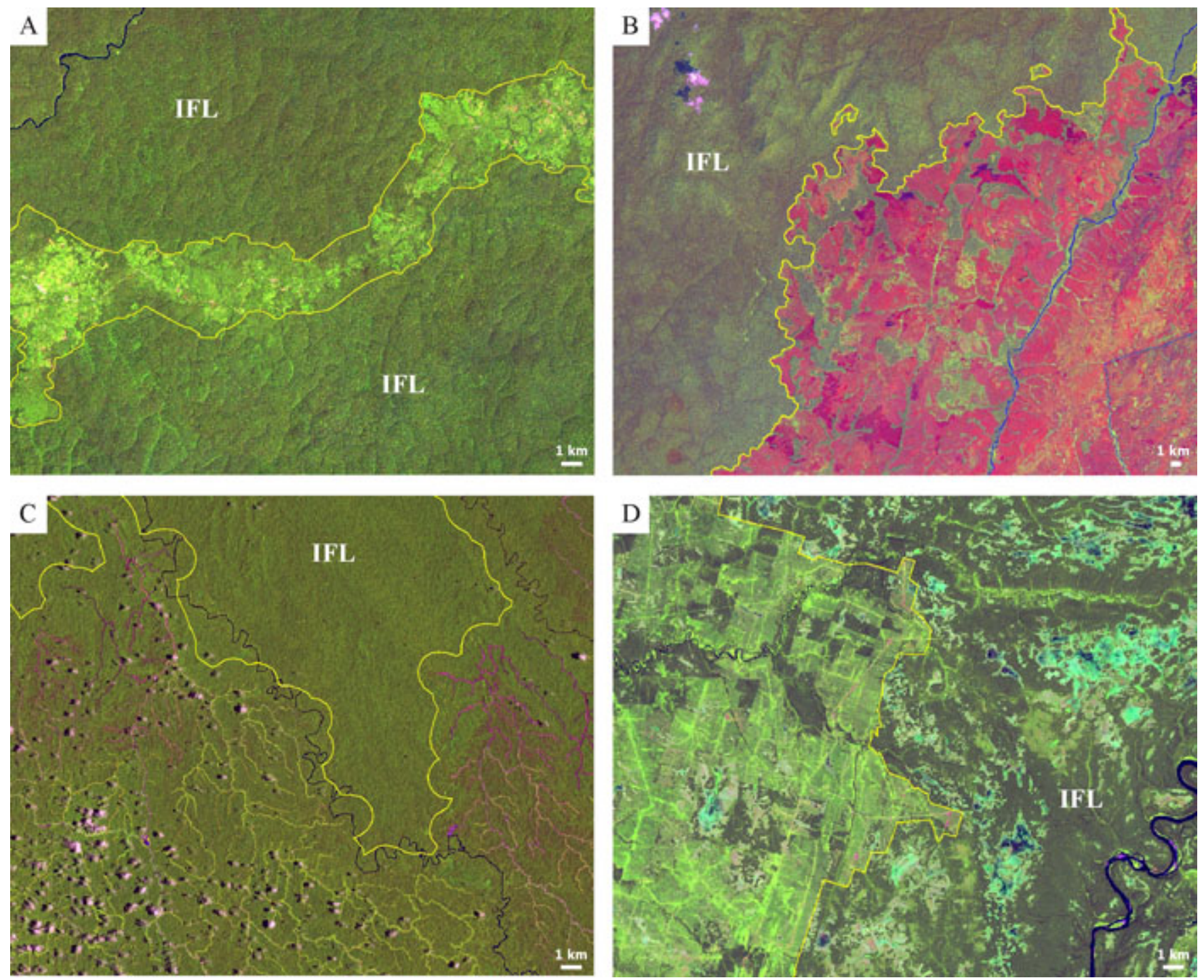

\section{Intactness of Forest Biomes}

Comprehensive mapping of IFLs makes it possible to study the degree of intactness of different biomes. We modified the world map of terrestrial ecoregions (Olson et al. 2001), aggregating the biomes into five groups as shown in Table 1, to produce major biome boundaries.
The vast majority of the world's remaining IFLs are found in "Dense Tropical and Subtropical Forests" $(45.3 \%)$ and in "Boreal Forests" (43.8\%) (Table 1). Within these biomes, the human influence is unevenly distributed. More than half of the IFL area of "Dense Tropical and Subtropical Forests" is found in South America, whereas IFLs are largely absent in the lowlands of continental Asia. Across 
Fig. 2. The world's intact forest landscapes (IFLs): IFL (green), Forest zone outside IFL (yellow).

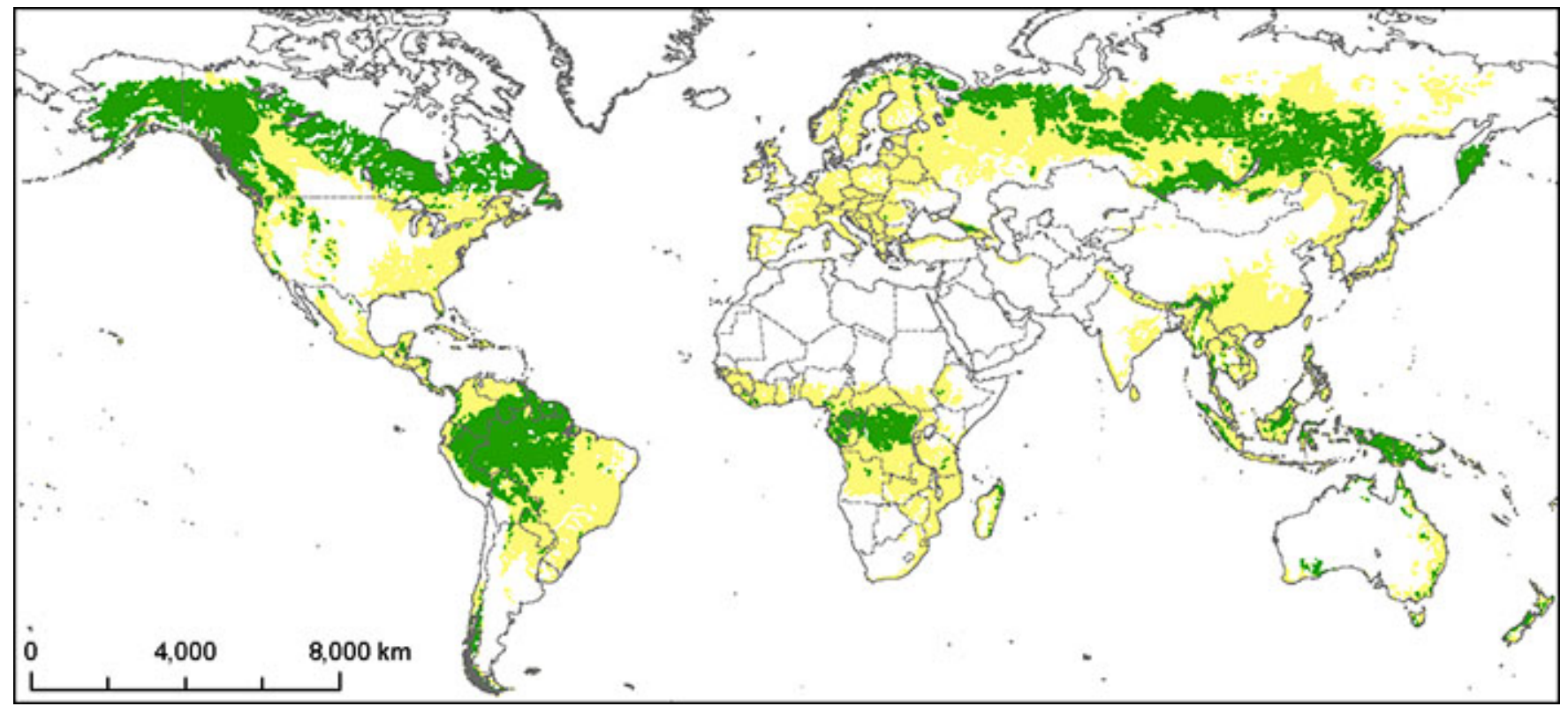

the "Boreal Forests" of northern Eurasia and North America, the proportion of IFLs is consistently greater in the north than in the south, with the exception of northwestern Europe, where IFLs have nearly disappeared.

The "Temperate Broadleaf and Mixed Forests" biome is almost totally devoid of IFLs because of its high population density and long history of agricultural and economic development. The small patches of IFL that do exist are in mountainous areas and within areas dominated by large wetlands. The "Temperate Coniferous Forests" of the Pacific coast of North America are the least disturbed of the temperate forest biomes due to its location in a mountainous landscape with limited suitability for agriculture.

The sparsely wooded "Tropical and Subtropical Woodlands and Savannas" are much more affected by human influence than the denser forest biomes because of extensive agriculture, clearing of land for pastures, and intensive use of fire for grassland productivity improvement and hunting. The long history of periodic human-caused fires has converted these woodlands into extremely pyrogenic savannas and grassland communities.
Grazing and burning are less common in the high mountains of the "Montane Grasslands and Shrublands" than in the "Tropical and Subtropical Woodlands and Savannas." It is possible that the area of IFLs has been overestimated in this biome, however, as the heterogeneity of the landscape and the lack of reliable information about conditions on the ground make the interpretation of satellite images difficult.

The tree canopy density in human-influenced areas is generally different from that of IFLs, reflecting historical differences in forest and land use (Fig. 3). In biomes where economic activity has required that forests be cleared for agriculture ("Dense Tropical and Subtropical" and "Temperate Broadleaf and Mixed Forest") or for grazing ("Tropical and Subtropical Woodland and Savanna"), the canopy density is generally higher within IFLs than outside. The opposite is true where industrial development has fragmented the landscape and secondary forests have appeared after fire and logging ("Boreal" and "Temperate Coniferous Forests," "Montane Grassland and Shrubland"). Remaining IFLs in these biomes are usually found in less productive northern and high-elevation areas where sparse forests and naturally treeless areas are common. 
Table 1. Distribution of IFLs within major forest biomes.

\begin{tabular}{|c|c|c|}
\hline Biome & $\begin{array}{r}\text { Proportion of IFLs in this } \\
\text { biome, } \%\end{array}$ & $\begin{array}{r}\text { Proportion of the world's } \\
\text { IFLs, \% }\end{array}$ \\
\hline $\begin{array}{l}\text { Dense Tropical and Subtropical Forests } \\
\text { (group of Tropical and Subtropical Moist Broadleaf Forests } \bullet \\
\text { Tropical and Subtropical Dry Broadleaf Forests • Tropical and } \\
\text { Subtropical Coniferous Forests } \bullet \text { Mangroves) }\end{array}$ & 29.9 & 45.3 \\
\hline $\begin{array}{l}\text { Tropical and Subtropical Woodlands and Savannas } \\
\text { (group of Tropical and Subtropical Grasslands, Savannas, and } \\
\text { Shrublands } \bullet \text { Flooded Grasslands and Savannas } \bullet \text { Mediterranean } \\
\text { Forests, Woodlands, and Scrub } \bullet \text { Deserts and Xeric Shrublands) }\end{array}$ & 3.1 & 2.5 \\
\hline $\begin{array}{l}\text { Temperate Broadleaf and Mixed Forests } \\
\text { (group of Temperate Broadleaf and Mixed Forests • Temperate } \\
\text { Grasslands, Savannas and Shrublands) }\end{array}$ & 3.7 & 2.3 \\
\hline Temperate Coniferous Forests & 19.5 & 4.9 \\
\hline $\begin{array}{l}\text { Boreal Forests } \\
\text { (group of the Boreal Forests / Taiga } \bullet \text { Tundra) }\end{array}$ & 43.6 & 43.8 \\
\hline Montane Grasslands and Shrublands & 25.6 & 1.2 \\
\hline
\end{tabular}

\section{Country-Level Analysis}

To develop a global strategy for forest conservation, the IFL extent has been analyzed for individual countries. We analyzed the distribution of IFLs within the 149 countries of the forest zone. Intact forest landscapes were found in 66 of these countries. The IFL proportion of the forest area is small in most countries-less than $10 \%$ in 33 countries. Only in five countries do IFLs occupy more than half of the forest zone (Canada, French Guyana, Guyana, Peru, and Surinam). Most of the world's IFL area is concentrated in a small number of countries-13 countries contain $90 \%$ of the total IFL area, and three of them-Canada, Russia, and Brazil-alone contain $63.8 \%$ of the world's entire IFL area.

We used the World Database of Protected Areas (WDPA) (2007) to assess the protection status of IFLs. The analysis comprised all national and international protected areas belonging to IUCN Categories I-VI and represented by spatial boundaries in the database. We found that $18.9 \%$ of the world's IFL area is protected in some form, but only $9.7 \%$ is strictly protected, i.e., belongs to any of the IUCN categories I-III. The protected proportion varies among biomes and countries. At the low end, 29 countries have placed less than $10 \%$ of the IFL area under strict protection. At the high end, seven countries-Cote d'Ivoire, Costa Rica, Finland, New Zealand, Nigeria, Sweden, and Thailand-have protected more than $50 \%$ of their IFL area. The protected portion is greatest in "Temperate Broadleaf and Mixed Forests" and smallest in "Boreal Forests," where no more than $4.4 \%$ of the IFL area is strictly protected. Among the continents, the protected proportion is smallest in Asia. Some Asian countries-China, Cambodia, Laos, and Vietnam - have placed little or none of their IFL area under protection.

\section{Comparison with Previous Studies}

Our results differ somewhat from previous global analyses of human disturbance and fragmentation rates (Table 2, Fig. 4). We found significantly less intact area in boreal forests than the World's Wilderness Areas analysis (McCloskey and Spalding 1989) and the Frontier Forests analysis (Bryant et al. 1997) because of our more recent data 
Fig. 3. Tree canopy density inside IFL (i) and outside IFL (o) for different biomes (DTSF - Dense Tropical and Subtropical Forest; TSWS - Tropical and Subtropical Woodland and Savanna; TBMF Temperate Broadleaf and Mixed Forest; TCF - Temperate Coniferous Forest; BF - Boreal Forest; MGS Montane Grassland and Shrubland).

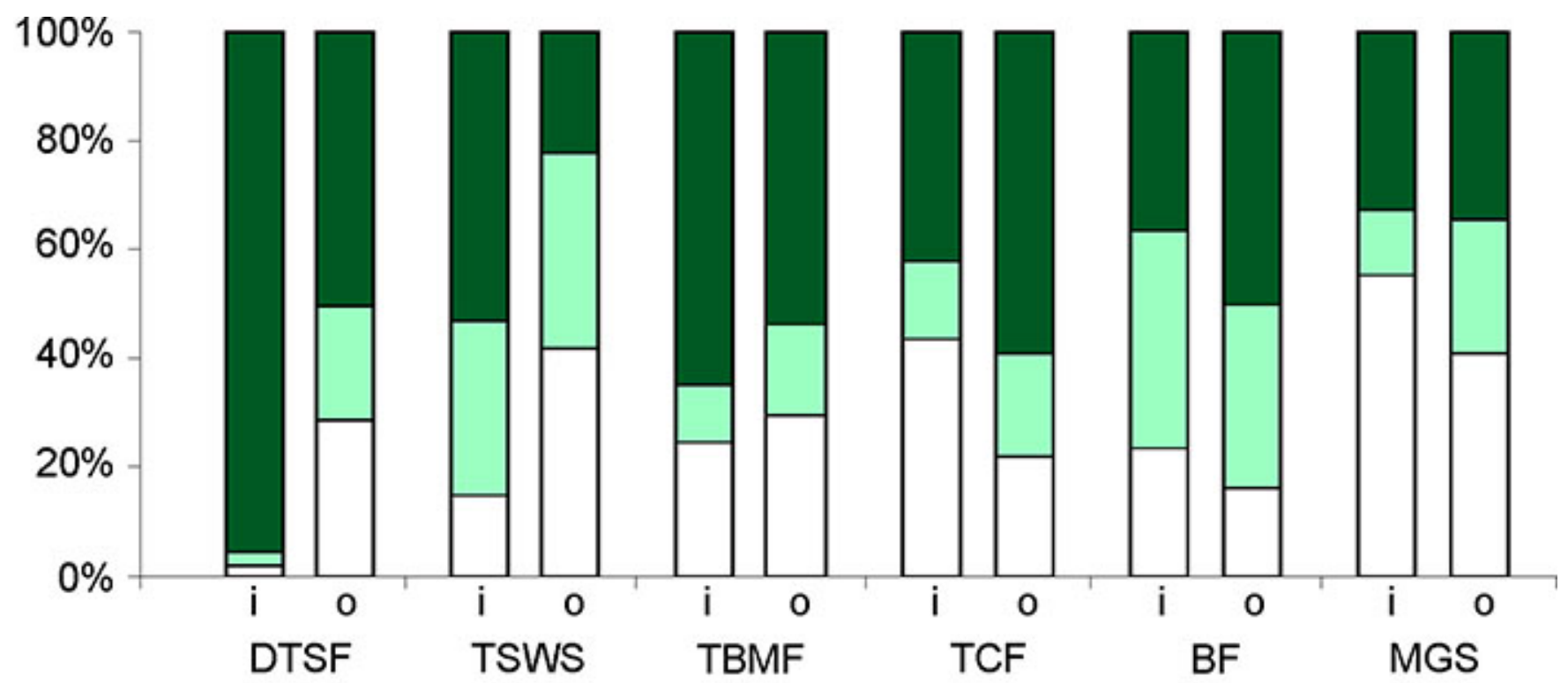

\section{$\square$ Closed forests $\square$ Open forests and woodlands}

allowing us to capture the effect of the expansion of oil and gas extraction infrastructure in Canada and Siberia, as well as the role of extensive humancaused fires accompanying industrial development of northern forests. On the other hand, our results show more intact areas in dense tropical forests (the Amazon and Congo basins) and in boreal mountains (southern and eastern Siberia, Kamchatka, Alaska, and the Canadian Rocky Mountains) than was found in previous studies based on coarse-scale map and expert data analysis. The difference is even greater in comparison with the Human Footprint data set (Sanderson et al. 2002), which finds a significantly larger area to be intact within boreal regions and the southern part of the Amazon Basin in Brazil. Both areas were developed (by industrial logging and oil and gas extraction in Canada and Russia, and by agricultural clearing in Brazil) in recent decades, and these changes were not captured in the Human Footprint assessment. Additionally, in some regions (i.e., Central Africa, boreal forests in Siberia and Canada) we found a smaller area to be intact than the Human Footprint map because we classified burned areas in the vicinity of infrastructure as not intact. The Landscape Domestication Analysis by The Nature Conservancy, which relied on existing transportation network maps, also overestimated the intact area (Kareiva et al. 2007).

\section{DISCUSSION}

\section{Intact Forest Landscape Mapping and Monitoring as a Tool to Assess Forest Degradation}

The negative role of forest loss and degradation, including fragmentation of natural landscapes, in global climate change and biodiversity loss is well known (Harris 1984, Bryant et al. 1997, FAO 2002, Hassan et al. 2005). The global rates of forest degradation are uncertain, however (Mollicone et al. 2007). Although our knowledge concerning the rates of deforestation has been greatly improved in the last few years through the use of remote-sensing 
Table 2. Comparison of different assessments of the world's intact forest area (within the forest zone).

\begin{tabular}{|c|c|c|c|}
\hline Type of intact area & Minimum size, $\mathrm{km}^{2}$ & Main data source & $\begin{array}{l}\text { Proportion intact, } \\
\%\end{array}$ \\
\hline $\begin{array}{l}\text { Wilderness areas (McCloskey and } \\
\text { Spalding 1989) }\end{array}$ & 4000 & Jet Navigation Charts & 21.1 \\
\hline Frontier forests (Bryant et al. 1997) & $\begin{array}{l}\text { Inconsistent, but } \\
>500\end{array}$ & Expert information & 21.8 \\
\hline $\begin{array}{l}\text { Areas with minimal }(0-10) \text { human } \\
\text { influence index derived from Human } \\
\text { Footprint data set (Sanderson et al. 2002) }\end{array}$ & 500 & $\begin{array}{l}\text { Coarse-scale global maps and low } \\
\text { spatial resolution remote-sensing } \\
\text { data analysis results }\end{array}$ & 38.0 \\
\hline Intact Forest Landscapes (this study) & 500 & $\begin{array}{l}\text { High spatial resolution satellite } \\
\text { images }\end{array}$ & 23.5 \\
\hline
\end{tabular}

data (Achard et al. 2002, FAO 2005, Hansen et al. 2008, Potapov et al. 2008), the forest degradation estimates, as a general rule, remain accurate only at the local level (Matthews et al. 2000). Estimating degradation is difficult because of the great variability in the forms, factors, and degrees of human impact.

A simple and feasible way to cope with this complexity is to use changes in forest intactness as a proxy for forest degradation. The boundary between "intact" and "non-intact" forest landscapes provided by this study has several advantages as a baseline: (1) it provides a detailed snapshot of the ecological integrity of the world's forest biomes at the beginning of the new millennium (approximately year 2000); (2) the mapping method can be easily adapted into a monitoring method that uses the same type of data (high spatial resolution satellite images); and (3) its high precision and fine scale make it a meaningful baseline for analysis of the small-scale disturbances that can be detected by remotely sensed data.

The primary source of data for the IFL map - high spatial resolution satellite images-has several advantages for future monitoring, including allowing direct and precise mapping of disturbances and new infrastructure, precise estimation of the area of change, and classification of disturbances by type. Therefore, we propose to use visual interpretation of high spatial resolution satellite imagery within IFL areas as the main monitoring algorithm. This data source also has some disadvantages, however: high cost, long expected average time between cloud-free images of the same area, and long time for data analysis, necessitating a long change detection interval (up to $3-5$ years).

An alternative source of data, allowing annual monitoring, would be medium spatial resolution images, especially MODerate Resolution Imaging Spectroradiometer (MODIS) data. MODIS data are available free of charge and can be obtained on a regular basis. Recent research shows that MODISderived forest change data can be used for precise estimation of forest cover loss (using Landsat-based calibration), and for displaying the spatial and temporal patterns of forest-cover change (Shimabukuro et al. 2004, Hansen et al. 2008, Potapov et al. 2008). MODIS red and NIR bands with a spatial resolution of $250 \mathrm{~m}$ per pixel could be used to detect largescale disturbances (i.e., logging in boreal forests and industrial agriculture clearings in the tropics) using visual interpretation. The disadvantages are that MODIS data do not allow identification of smallscale disturbances (such as small-scale agriculture in tropical Africa and Asia), scattered disturbances (intensive selective logging), or most elements of transportation infrastructure. A combination of both approaches might be the best solution for a longterm monitoring strategy. This would entail using MODIS data for annual large-scale change detection and high spatial resolution images for fine-scale change detection and fragmentation analysis at longer (3-5 years) intervals. 
Fig. 4. Comparison of (A) the Wilderness Areas map by McCloskey and Spalding (1989); (B) Frontier Forests map by Bryant et al. (1997); (C) Intact areas map produced on the base of the Human Footprint data set by Sanderson et al. (2002), and (D) IFL mapping results for different regions: I - Tropical Africa; II - Amazon basin; III - Canadian province Alberta.; Intact areas (green); the rest of forest zone (gray).
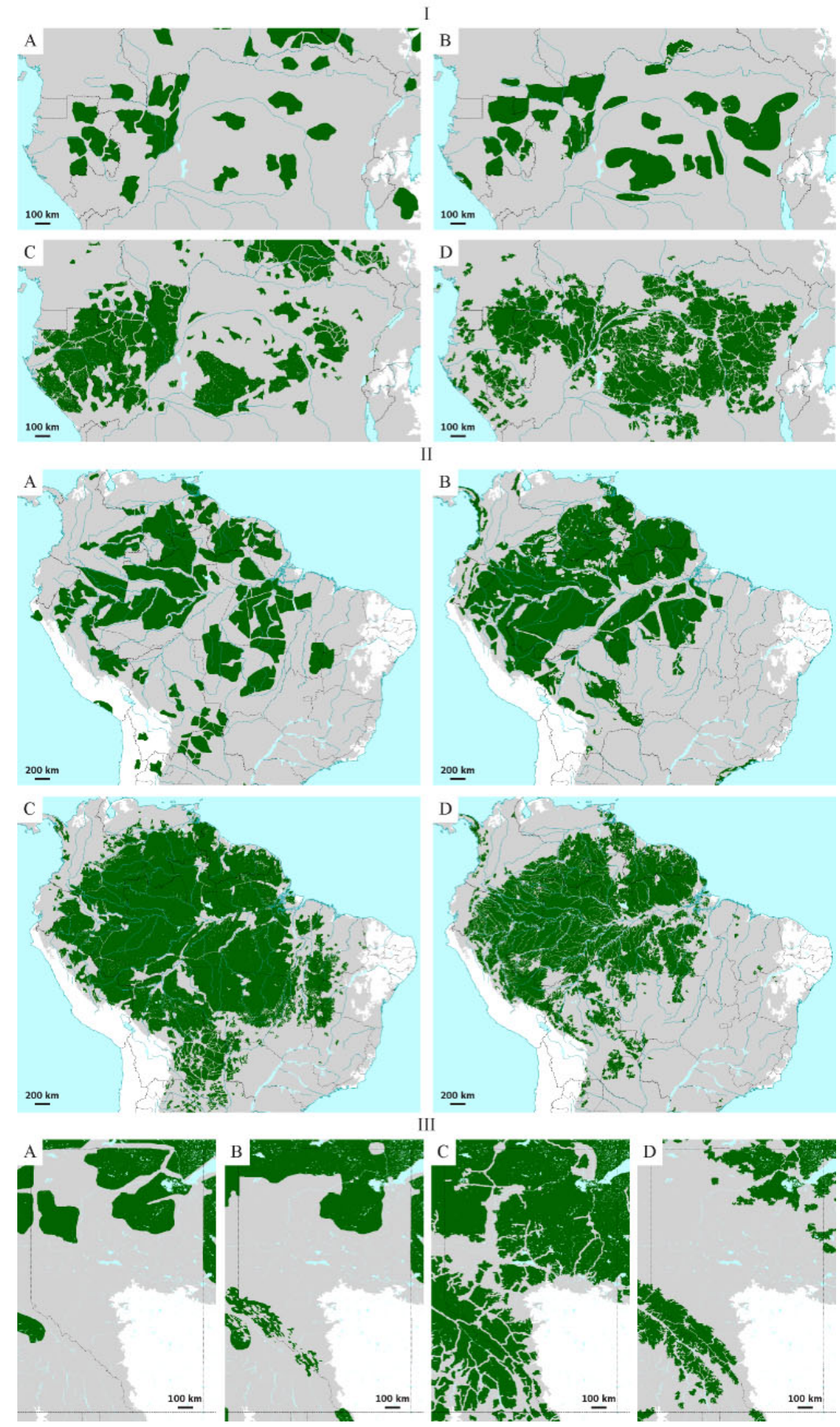


\section{Intact Forest Landscape Maps as a Tool to Develop Strategies for Nature Conservation}

The only way to maintain the full range of values of an "intact" forest landscape is to maintain its intactness (engineered intactness is impossible by definition). The cost in terms of lost opportunities appears to be small in most cases. Most IFLs are remote and difficult to exploit-this is typically the reason why they are still intact — and are threatened mainly by the loss of more attractive forest resources and agricultural lands through degradation. The cost is low also in terms of effort. Large forest landscapes are significantly less expensive to protect than a large number of small fragments in an otherwise transformed landscape that will serve as a source of human pressure of different kinds. Moreover, the ecological integrity of large IFLs will allow them to maintain their value regardless of large natural disturbance events and long-term climate change (Yaroshenko et al. 2001).

Creation of large natural areas with strict protection rules (IUCN categories I-III) should therefore be considered, particularly in places where the level of threat is high. A complementary approach, especially important in areas where the formal process of creating protected areas is slow, is market protection. Several companies have committed not to use wood from IFLs unless intactness values are preserved, e.g., IKEA (2005) andLowe's (2008), or to invest only in companies that maintain such values, e.g., Bank of America (2008). These companies use regional maps produced with the method described in this study to implement these policies and avoid sourcing wood from intact forests.

The FSC has included a category of "High Conservation Value Forest" in its "Principles and Criteria for Forest Stewardship" (FSC 2004) whose definition is similar to that of intact forest landscapes: "Large landscape level forests, contained within, or containing the management unit, where viable populations of most if not all naturally occurring species exist in natural patterns of distribution and abundance." The FSC's Principle 9 requires that "Management activities in high conservation value forests shall maintain or enhance the attributes that define such forests. Decisions regarding high conservation value forests shall always be considered in the context of a precautionary approach." This means that intactness values must be preserved as a condition for getting certified. Some regional FSC standards, particularly the Canadian and Russian national standards, interpret this HCVF category as globally, nationally, or regionally significant forest landscapes unfragmented by permanent infrastructure and of a size to maintain viable populations of most species (FSC Canada Working Group 2004, FSC BC Regional Initiative 2005, Karpachevskiy and Chuprov 2007), allowing them to use regional IFL maps for certification of forest management. In the FSC Controlled Wood standard (FSC 2006) IFLs are directly mentioned among other categories of High Conservation Value Forests.

However, total protection of IFLs may be difficult in some cases for socioeconomic reasons. The most accessible and productive areas for food and timber production may already have been exhausted or degraded, and population growth and lack of other opportunities also increase pressure on remaining marginal areas. In such situations, an appropriate strategy may be to divide IFLs into zones. This would entail creating zones of strict nature protection (where the goal would be to preserve intactness values) and of low-impact management (in which limited forestry operations or small-scale farming with strict observance of ecological norms could take place).

\section{Advantages and Limitations of the IFL Concept and Map}

The global IFL map is based on a set of criteria and approaches that apply to all countries and continents, without differentiation. The use of a single set of criteria allowed us to produce a globally consistent map and derive estimates of the level of intactness. However, these criteria are not sensitive to regional variations in the understanding of "intactness" and "disturbance," e.g., whether burned areas should be considered the effect of natural disturbance or not. Furthermore, they were designed specifically for use with remotely sensed data. The mapping method is not immune to underestimation of some types of human disturbances that are difficult to detect in satellite imagery, such as selective logging and small-scale slash-and-burn agriculture practices. Therefore, our results are generally not immediately suitable for local-scale conservation planning, as our globally consistent criteria may be in conflict with locally used criteria and locally known disturbances may have been overlooked. They may be used as a 
framework for such projects, however, to complement additional locally relevant information.

Compared with previous intactness assessments, our analysis is based on an up-to-date, precise, and consistent data source (e.g., high spatial resolution satellite images) whereas earlier analyses have relied on expert data (Frontier Forests assessment), existing coarse-scale maps (Wilderness Areas assessment), or coarse-scale maps combined with low-resolution satellite-derived data sets (Human Footprint project). The use of comparatively current information allowed us to capture the effect of the recent expansion of industrial agriculture (in tropical forests), oil and gas extraction infrastructure (in Canada and Siberia), and logging that was not captured in previous studies (McCloskey and Spalding 1989, Bryant et al. 1997, Sanderson et al. 2002, Kareiva et al. 2007).

The world IFL map was created through visual interpretation of Landsat images by experts and may contain inconsistencies and inaccuracies because of limitations in the spatial resolution of the imagery and lack of ancillary information about local landuse practices in some regions. There is a certain degree of subjectivity in determining IFL boundaries across transition zones from intact to disturbed areas, especially within non-forest territories, savannas, woodlands, and mountain areas. The method is biased towards overestimating the area of IFL, as imperfect information will cause disturbances to be overlooked and disturbed areas to be classified as intact.

The authors envision that the map will be updated and improved periodically to reflect the continuing changes in IFLs. New data, technologies, and more sophisticated sources of information will gradually reduce the necessary effort. For this purpose, a continuous external review process has been organized on a dedicated web site (http://www.inta ctforests.org). All up-to-date IFL maps and IFL monitoring results are available online in formats suitable for use in professional GIS (ArcGIS $®$ ) as well as in freeware GIS browsers (GoogleEarth ${ }^{\mathrm{TM}}$ ). The map support team is reviewing all user feedback and revising the map as new evidence of disturbances becomes available.

\section{CONCLUSION}

We have presented a new approach for assessment of ecological integrity and intactness at the regionalto-global scale. At the core of this approach is a rapid and straightforward method for mapping and monitoring of IFLs that relies on publicly available high spatial resolution satellite imagery and finescale maps. Application of this method yielded the first global IFL map. This map makes it possible, for the first time, to quantify and compare the extent of remaining large natural forest areas worldwide. It also provides a suitable baseline for operational, cost-effective, satellite-based monitoring of forest loss and degradation, where its global scope and consistency is particularly useful for capturing issues of leakage. The map will be improved and updated based on feedback from local experts using a dedicated website for online review (http://www. intactforests.org).

Large intact landscapes contain entire natural mosaics of ecosystems. They sustain natural levels of populations and ecosystem diversity, play an important role in climate regulation, and maintain ecological processes and services such as water and air purification, nutrient cycling, carbon sequestration, erosion and flood control, etc. Conservation of large IFLs is a robust and cost-effective way to protect biodiversity and maintain ecological integrity and should therefore be an important component of a general conservation strategy. The remoteness and large size of these areas provide the best guarantee for their continued intactness. The world IFL map is a tool that supports the creation of such a strategy and enables monitoring of forest degradation. However, many landscapes have already been transformed to the point where only small undisturbed fragments remain, or even none at all. Mapping of conservation values in these landscapes is an important task that lies outside the scope of the work presented here.

Responses to this article can be read online at: http://www.ecologyandsociety.org/voll3/iss2/art51/responses/

\section{Acknowledgments:}

This world IFL map was prepared in 2005-2006 under the leadership of Greenpeace, with contributions from: Biodiversity Conservation 
Center, International Socio-Ecological Union, and Non-Commercial Partnership Transparent World (Russia), Luonto Liitto (Finnish Nature League), Forest Watch Indonesia, and Global Forest Watch, a network initiated by the World Resources Institute. The IFL mapping criteria and methods were originally developed and tested in Russia (Yaroshenko et al. 2001, Aksenov et al. 2002). We greatly appreciate the number of remote-sensing data interpretation specialists, GIS technicians, and regional experts who provided invaluable knowledge and assistance in the development of this map. Special thanks to V. Fedorov, R. Kiselev, K. Kobyakov, A. Kostikova, S. Minnemeyer, B. Musin, A. Purekhovsky, O. Turunen, T. Yanitskaya, and A Yumakaev, for their support in data analysis. We thank F. Achard, P. Angelstam, T. Braslavskaya, $H$. Cui, H. D. Eva, M. C. Hansen, A. Isaev, H. Liu, P. Mayaux, M. Ohsawa, R. Ridder, O. Smirnova, V. Snakin, and H.-J. Stibig for reviewing the IFL concept and map. We thank V. Roshchanka, S. Minnemeyer, T. Sadownichik, M. C. Hansen and V. C. Radelofffor reviewing earlier drafts of this paper. The work was supported, in its entirety or in part, by Greenpeace International, the home-furnishing company IKEA, the Swedish International Development and Cooperation Agency (SIDA), the John D. and Catherine T. MacArthur Foundation, the Turner Foundation, and the World Resources Institute.

\section{LITERATURE CITED}

Achard, F., H. D. Eva, H.-J. Stibig, P. Mayaux, J. Gallego, T. Richards, and J.-P. Malingreau. 2002. Determination of deforestation rates of the world's humid tropical forests. Science 297:999-1002.

Aksenov, D., D. Dobrynin, M. Dubinin, A. Egorov, A. Isaev, M. Karpachevskiy, L. Lestadius, P. Potapov, A. Purekhovskiy, S. Turubanova, and A. Yaroshenko. 2002. Atlas of Russia's intact forest landscapes. Global Forest Watch, Moscow, Russia. [online] URL: http://www globalforestwatch.org/common/russia/Atlas report pdfs/ Cover-032.pdf.

Anderson, J. E. 1991. A conceptual framework for evaluating and quantifying naturalness. Conservation Biology 5:347-352.
Bank of America Corporation. 2008. Bank of America forests practices-global corporate investment bank policy. [online] URL: http://www. bankofamerica.com/environment/index.cfm?template $=$ env workrel.

Bryant, D., D. Nielsen, and L. Tangley. 1997. The last frontier forests: ecosystems and economies on the edge. World Resources Institute (WRI), Washington, D.C., USA. [online] URL: http://www .globalforestwatch.org/english/pdfs/Last Frontier Forests. pdf.

Dixon, R. K. 1994. Carbon pools and flux of global forest ecosystems. Science 263:185-190.

Ferraz, G., G. J. Russell, P. C. Stouffer, R. O. Bierregaard, S. L. Pimm, and T. E. Lovejoy. 2003. Rates of species loss from Amazonian forest fragments. Proceedings of the National Academy of Sciences 100:14069-14073.

Food and Agriculture Organization (FAO). 2002. Assessing forest integrity and naturalness in relation to biodiversity. Working Paper 54. FAO, Rome, Italy. [online] URL: http://www.fao.org/doc rep/006/ad654e/ad654e00.htm.

- 2005. State of the world's forests. FAO, Rome, Italy. [online] URL: http://www.fao.org/doc rep/007/y 5574e/y 5574e00.htm.

Forest Stewardship Council (FSC). 2004. FSC International standard. FSC principles and criteria for forest stewardship (FSC-STD-01-001). FSC, Bonn, Germany. [online] URL: http://www.fsc.org/ fileadmin/web-data/public/document center/ international FSC policies/standards/

FSC STD 01001 V4 0 EN FSC Principles an d Criteria.pdf.

- 2006. FSC standard for company evaluation of FSC Controlled Wood (FSCSTD-40-005). FSC, Bonn, Germany. [online] URL: http://www.fsc.org/fileadmin/web-data/public/ document center/international FSC policies/standards/ FSC STD 40005 V2 1 EN Company Evaluati on of Controlled Wood.pdf.

Forest Stewardship Council (FSC) British Columbia Regional Initiative. 2005. Forest Stewardship Council regional certification standards 
for British Columbia. FSC Canada, Toronto, Ontario, Canada. [online] URL: http://www.fsccan ada.org/BritishColumbia.htm.

Forest Stewardship Council (FSC) Canada Working Group. 2004. National boreal standard. FSC Canada, Toronto, Ontario, Canada. [online] URL: http://www.fsccanada.org/nationalBoreal.htm

Gucinski, H., M. J. Furiss, R. R. Ziemer, and M. H. Brookes. 2001. Forest roads: a synthesis of scientific information. USDA, Portland, Oregon. [online] URL: http://www.fs.fed.us/pnw/pubs/gtr509. pdf.

Hansen, M. C., R. S. DeFries, J. R. G.Townshend, M. Carroll, C. Dimiceli, and R.A. Sohlberg. 2003. Global percent tree cover at a spatial resolution of 500 meters: first results of the MODIS vegetation continuous fields algorithm. Earth Interactions 7:115. DOI: 10.1175/1087-3562(2003)007.

Hansen, M. C., S. V. Stehman, P. V. Potapov, T. R. Loveland, J. R. G. Townshend, R. S. DeFries, K. W. Pittman, F. Stolle, M. K. Steininger, M. Carroll, and C. Dimiceli.2008. Humid tropical forest clearing from 2000 to 2005 quantified using multi-temporal and multi-resolution remotely sensed data. Proceedings of the National Academy of Science 105(27):9439-9444.

Harris, L. D. 1984. The fragmented forest: island biogeography theory and the preservation of biotic diversity. The University of Chicago Press, Chicago, Illinois, USA.

Hassan, R. M., R. Scholes, and N. Ash, editors. 2005. Ecosystems and human well-being: current state and trends: findings of the Condition and Trends Working Group. Millennium Ecosystem Assessment Series, volume 1. Island Press, Washington, D.C., USA. [online] URL: http://www .millenniumassessment.org/en/index.aspx.

Houghton, R. A., D. L. Skole, and D. S. Lefkowitz.1991. Changes in the landscape of Latin America between 1850 and 1985 II. Net release of $\mathrm{CO}_{2}$ to the atmosphere. Forest Ecology and Management 38:173-199.

IKEA Trading und Design AG.2005. IWAY Standard. [online] URL: http://www.ikea-group.ikea. com/repository/documents/917.pdf.
International Geosphere-Biosphere Programme, Terrestrial Carbon Working Group (IGBP).1998. The terrestrial carbon cycle: implications for the Kyoto Protocol. Science 280:1393-1394.

Iverson, L. R., R. L. Graham, and E. A. Cook. 1989. Applications of satellite remote sensing to forested ecosystems. Landscape Ecology 3(2):131143.

Kareiva, P., S. Watts, R. McDonald, and T. Boucher. 2007. Domesticated nature: shaping landscapes and ecosystems for human welfare. Science 316:1866-1869.

Karpachevskiy M., and V. Chuprov, editors. 2007. Russian national standard for FSC certification. Russian National Initiative of Forest Stewardship Council, Moscow, Russia. [online] URL: http://www.fsc.ru/pdf/RNS.pdf.

Lowe's. 2008. Lowe's policy on the wood contained in its products. [online] URL: http://www.lowes.com/ lowes/lkn?action=pg\&p=PressReleases/wood policy. $\underline{\mathrm{html}}$.

Matthews, E., R. Payne, M. Rohweder, and S. Murray. 2000. Pilot analysis of global ecosystems: forest ecosystems. World Resources Institute, Washington, D.C., USA. [online] URL: http://www .wri.org/publication/pilot-analysis-global-ecosystemsforest-ecosystems\#.

McCloskey, J. M., and H. Spalding. 1989. A reconnaissance level inventory of the amount of wilderness remaining in the world. Ambio $\mathbf{1 8}$ (4):221-227.

Mollicone, D., F. Achard, S. Federici, H. D. Eva, G. Grassi, A. Belward, F. Raes, G. Seufert, H.-J. Stibig, G. Matteucci, and E.-D. Schulze. 2007. An incentive mechanism for reducing emissions from conversion of intact and non-intact forests. Climatic Change 83:477-493.

Mollicone, D., H. D. Eva, and F. Achard. 2006. Human role in Russian wild fires. Nature 440 (23):436-437.

Mouillot, F., and C. B. Filed. 2005. Fire history and the global carbon budget: a $1^{\circ} \mathrm{x}^{\circ} 1$ fire history reconstruction for the 20th century. Global Change Biology 11:398-420. 
Noss, R. F. 1990. Can we maintain biological and ecological integrity? Conservation Biology 4 (3):241-243.

Olson, D. M., E. Dinerstein, E. D. Wikramanayake, N. D. Burgess, G. V. N. Powell, E. C. Underwood, J. A. D'amico, I. Itoua, H. E. Strand, J. C. Morrison, C. J. Loucks, T. F. Allnutt, T. H. Ricketts, Y. Kura, J. F. Lamoreux, W. W. Wettengel, P. Hedao, and K. R. Kassem. 2001. Terrestrial ecoregions of the World: A new map of life on Earth. BioScience 51(10): 1-6.

Potapov P., M. C. Hansen, S. V. Stehman, T. R. Loveland, and K. Pittman. 2008. Combining MODIS and Landsat imagery to estimate and map boreal forest cover loss. Remote Sensing of Environment 112(9):3708-3719.

Rodriguez, A., and M. Delibes. 2003. Population fragmentation and extinction in the Iberian lynx. Biological Conservation 109(3):321-331

Rudis, V. A., and J. B. Tansey. 1995. Regional assessment of remote forests and black bear habitat from resource surveys. Journal of Wildlife Management 59(1):170-180.

Sanderson, E. W., M. Jaiteh, M. A. Levy, K. H. Redford, A. V. Wannebo, and G. Woolmer. 2002. The human footprint and the last of the wild. BioScience 52(10):891-904.

Secretariat of the Convention on Biological Diversity (SCBD). 2001. The value of forest ecosystems. SCBD, Montreal, Quebec, Canada. [online] URL: http://www.cbd.int/doc/publications/ cbd-ts-04.pdf.

Shimabukuro, Y. E., V. Duarte, L. O. Anderson, E. Arai, D. M. Valeriano, F. D. B. Espirito Santo, and L. C. M. Aulicino. 2004. Deforestation detection in Brazilian Amazon region in a near real time using Terra MODIS daily data. IEEE Geoscience and Remote Sensing Symposium Proceedings 5:3405-3408.

Tucker, C. J., D. M. Grant, and J. D. Dykstra. 2004. NASA's global orthorectified Landsat data set. Photogrammetric Engineering and Remote Sensing 70:313-322

Turner, I. M. 1996. Species loss in fragments of tropical rain forest: a review of the evidence. The Journal of Applied Ecology 33(2):200-209.

Wilcox, B. A., and D. D. Murphy. 1985. Conservation strategy: the effects of fragmentation on extinction. American Naturalist 125:879-887.

Woodcock, C. E., S. A. Macomber, M. PaxLenney, and W. B. Cohen. 2001. Monitoring large areas for forest change using Landsat: generalization across space, time and Landsat sensors. Remote Sensing of Environment 78:194-203.

World Database on Protected Areas (WDPA). 2007. UNEP-WCMC and IUCN World Commission on Protected Areas - December 2007. [online] URL: http://www.unep-wcmc.org/wdpa/.

Yaroshenko, A. Y., P. V. Potapov, and S. A. Turubanova. 2001. The last intact forest landscapes of northern European Russia. Greenpeace Russia and Global Forest Watch, Moscow, Russia. [online] URL: http://www.global forestwatch.org/english/russia/pdf/GFW Russia R eport en.pdf. 